RS2005.tex

\title{
Eurosystem Monetary Targeting: Lessons from U.S. Data*
}

\author{
Glenn D. Rudebusch ${ }^{\dagger} \quad$ Lars E.O. Svensson ${ }^{\ddagger}$
}

First draft: May 1999

This version: May 2000

\begin{abstract}
Using a small empirical model of inflation, output, and money estimated on U.S. data, we compare the relative performance of monetary targeting and inflation targeting. The results show that monetary targeting would be quite inefficient, with both higher inflation and output variability. This is true even with a nonstochastic money demand formulation. Our results are also robust to using a $P^{*}$ model of inflation. Therefore, in these popular frameworks, there is no support for the prominent role given to money growth in the Eurosystem's monetary policy strategy.
\end{abstract}

JEL Classification: E42, E52, E58

Keywords: inflation targeting, monetary targeting, ECB

\footnotetext{
${ }^{*}$ We thank Jordi Gali, Henrik Jensen, Edward Nelson, Athansios Orphanides, David Small, Ulf Söderström and the editors and two anonymous referees for comments, Niloofar Badie for research assistance, and Christina Lönnblad for editorial and secretarial assistance. The views expressed in the paper do not necessarily reflect the views of the Federal Reserve Bank of San Francisco or the Federal Reserve System.

${ }^{\dagger}$ Federal Reserve Bank of San Francisco; Glenn.Rudebusch@sf.frb.org, http://www.frbsf.org/econrsrch/ economists/grudebusch.html.

${ }^{\ddagger}$ Institute for International Economic Studies, Stockholm University; CEPR and NBER; Lars.Svensson@ iies.su.se, http://www.iies.su.se/leosven/.
} 


\section{Introduction}

The recent formation of a new monetary institution in Europe has, once more, highlighted the question of the proper role for money in the conduct of monetary policy. In the past few years, particularly during the gestation of the European Central Bank (ECB), a lively debate has considered whether monetary targeting or inflation targeting would be the most appropriate monetary strategy for the Eurosystem. ${ }^{1}$ This debate was only spurred on by the Eurosystem's announcement of its actual monetary strategy. As described in the inaugural issue of the ECB's Monthly Bulletin [10, p. 9]:

... [T] he strategy is based on two pillars. The first consists in a prominent role for money, as signalled by the announcement of a quantitative reference value of 4-1/2 percent for the growth rate of the broad monetary aggregate M3 which is regarded as being compatible with price stability. The second comprises a broadly based assessment of the outlook for price developments and the risks to price stability using financial and other economic indicators.

This strategy appears to be a combination of a weak type of monetary targeting and an implicit form of inflation targeting. It is only a weak type of monetary targeting because the Eurosystem has rejected a simple formulation in which money growth is an intermediate target variable to always be brought in line with the reference value. Nevertheless, the Eurosystem has made it clear that deviations of money growth from the reference value will be treated as a major factor in its policy decisions. The second pillar contains the basic thrust of inflation targeting; however, some of the important elements of an explicit inflation targeting strategy, such as the public comparison of an inflation forecast to an announced target, are absent.

In order to understand the potential for success of this mixed strategy for monetary policy, this paper evaluates the relative performance of monetary targeting and inflation targeting. This exercise provides, in a loose sense, some evidence of the relative value of the first and second pillars of Eurosystem strategy. Previous analysis in Svensson [41], [42], and [44] provides a theoretical case for favoring inflation targeting over monetary targeting. In this paper, we provide an empirical counterpart to this analysis using a small estimated model of inflation, output, and money.

Of course, an important difficulty for our analysis, or indeed any empirical investigation of the policy choice faced by the Eurosystem, is the lack of a data set with which to estimate an

\footnotetext{
1 The Eurosystem, which consists of the ECB and the national central banks of the 11 countries that have adopted the euro, has conducted monetary policy for the euro area since January 1, 1999.
} 
empirical model of the euro-area economy. The 11 nations of the euro area have been bound together with a common currency for only a very short period, so using appropriate postunion euro-area data for model estimates is not an option. Constructing synthetic pre-union aggregates from the separate historical data for the 11 euro-area countries is one alternative. ${ }^{2}$ This, of course, is an ambiguous counter-factual exercise. National statistics with differing definitions must be aggregated, and some accounting must be made of the actual historical exchange rate fluctuations among the 11 euro-area countries. Furthermore, even if unambiguous pre-union aggregates were available, it is not clear that the experience of the euro area before monetary union under floating exchange rates and with a variety of monetary policy regimes and institutions would be appropriate for analyzing the post-union euro area under the Eurosystem. Thus, reconstructed historical euro-area data will be an uncertain guide to the future. The experience of the United States is, in our opinion, at least as relevant a guide. It is often noted that the euro area has many similarities to the United States - obviously in terms of a monetary union - but also in economic size and in the relative importance of external trade. Accordingly, in analyzing the relative value of monetary targeting and inflation targeting, we use coefficients in our model that are estimated using U.S. data. We certainly cannot guarantee that this empirical model, which is merely a rudimentary approximation of the U.S. economy, is the correct vehicle for analyzing euro-area monetary policy in the future; however, as outlined in the next section, we think that our model has some desirable attributes even from a European perspective. Still, a major caveat to our analysis is that the economy in the euro-area under the Eurosystem may behave substantially different from the U.S. experience (or from a reconstructed euro-area history). ${ }^{3}$

With that caveat clearly established, our results from a model fit to the U.S. economy are used to draw some lessons for the Eurosystem. Our results show that monetary targeting is much more inefficient, in the sense of inducing more variable inflation and output, than inflation targeting. We get this result even after excluding parts of the sample period so as to estimate a very well-behaved, nonstochastic money-demand equation. Furthermore, this result is true even if we assume that there are no stochastic shocks at all affecting money demand. Thus, counter to conventional wisdom, monetary targeting is inefficient even if money demand is stable and controllable. This result reflects the fact that given the dynamics of how money is related to the

\footnotetext{
${ }^{2}$ This route is followed by Peersman and Smets [33] and Taylor [49], who use data from a subset of the 11 euro-area countries, and Gerlach and Svensson [14], who use data for the whole euro area.

${ }^{3}$ Indeed, for what it is worth, as noted in section 2, the work of Peersman and Smets [33] and Taylor [49] suggests that the equations of our model also have some claim to fit the pre-union synthetic euro-area data.
} 
rest of the economy, money growth is a poor predictor of future inflation (in the sense that the correlation between money growth and inflation forecasts is quite low). Thus, money growth is an inadequate indicator of risks to price stability. All this provides substantial empirical confirmation of the theoretical arguments in Svensson [41], [42], and [44].

Section 2 presents the model and the empirical estimates. Section 3 reports the results on the relative performance of inflation targeting and monetary targeting. We also show that nominal GDP targeting - a close relative to monetary targeting-would be quite inefficient compared to inflation targeting. In section 3 , we also consider an alternative model that incorporates a $P^{*}$ equation for inflation, which has had some empirical success in both the U.S. (Hallman, Porter, and Small [17]) and in the euro area (Gerlach and Svensson [14]). However, even with the enhanced role for money in the $P^{*}$ model, we find no support for money-growth targeting, which provides empirical confirmation of the theoretical results of Svensson [46]. Section 4 discusses the lessons for the Eurosystem. Section 5 presents some conclusions.

\section{An Empirical Model of U.S. Output, Inflation, and Money}

\subsection{Aggregate supply and demand}

The two equations for output and inflation used for our baseline analysis, which are fully described in Rudebusch and Svensson [36], are

$$
\begin{aligned}
\pi_{t+1} & =\alpha_{\pi 1} \pi_{t}+\alpha_{\pi 2} \pi_{t-1}+\alpha_{\pi 3} \pi_{t-2}+\alpha_{\pi 4} \pi_{t-3}+\alpha_{y} y_{t}+\varepsilon_{t+1} \\
y_{t+1} & =\beta_{y 1} y_{t}+\beta_{y 2} y_{t-1}-\beta_{r}\left(\bar{\imath}_{t}-\bar{\pi}_{t}-\bar{r}\right)+\eta_{t+1}
\end{aligned}
$$

where $\pi_{t}$ is quarterly inflation in the GDP chain-weighted price index $\left(P_{t}\right)$ in percent at an annual rate, i.e., $\pi_{t} \equiv 4\left(p_{t}-p_{t-1}\right)$, where $p_{t}=100 \ln P_{t}, \bar{\pi}_{t}$ is four-quarter inflation in the

GDP chain-weighted price index, i.e., $\frac{1}{4} \Sigma_{j=0}^{3} \pi_{t-j}, i_{t}$ is the quarterly average federal funds rate in percent per year, $\bar{t}_{t}$ is the four-quarter average federal funds rate, i.e., $\frac{1}{4} \Sigma_{j=0}^{3} i_{t-j}$, and $y_{t}$ is the output gap, the relative gap between actual real GDP $\left(Q_{t}\right)$ and potential GDP $\left(Q_{t}^{*}\right)$ in percent, i.e., $100\left(Q_{t}-Q_{t}^{*}\right) / Q_{t}^{*}$ (approximately $q_{t}-q_{t}^{*}$, where $q_{t} \equiv 100 \ln Q_{t}$ and $q_{t}^{*} \equiv 100 \ln Q_{t}^{*}$ are $\log$ GDP and log potential GDP scaled by 100, respectively). The series on potential GDP $\left(Q_{t}^{*}\right)$ is obtained from the Congressional Budget Office [7]. The constant $\bar{r}$ is the average real interest rate, and $\varepsilon_{t}$ and $\eta_{t}$ are iid shocks with variances $\sigma_{\varepsilon}^{2}$ and $\sigma_{\eta}^{2}$. The five variables were de-meaned prior to estimation, so no constants appear in the equations and $\bar{r}$ is set equal to zero. 
Estimated versions of these equations, using the sample period 1961:1 to 1996:4, are (with coefficient standard errors given in parentheses)

$$
\begin{aligned}
& \pi_{t+1}=\underset{(.083)}{.675 \pi_{t}} \underset{(.103)}{.077 \pi_{t-1}}+\underset{(.107)}{.286 \pi_{t-2}}+\underset{(.088)}{.115 \pi_{t-3}}+\underset{(.037)}{.152} y_{t}+\varepsilon_{t+1}, \\
& \overline{\mathrm{R}}^{2}=.81, \quad \mathrm{SE}=1.084, \quad \mathrm{DW}=1.99 \\
& y_{t+1}=\underset{(.079)}{1.161 y_{t}}-\underset{(.077)}{.259 y_{t-1}}-\underset{(.032)}{.088\left(\bar{\imath}_{t}-\bar{\pi}_{t}\right)}+\eta_{t+1} \\
& \overline{\mathrm{R}}^{2}=.90, \quad \mathrm{SE}=0.823, \quad \mathrm{DW}=2.08 .
\end{aligned}
$$

The equations were estimated individually by OLS. ${ }^{4}$ The hypothesis that the sum of the lag coefficients of inflation equals one had a $p$-value of .48 , so this restriction was imposed in estimation. Thus, this is an accelerationist form of the Phillips curve, which implies a long-run vertical Phillips curve. ${ }^{5}$

The use of this model can be motivated by a variety of considerations. In particular, although its simple structure facilitates the production of benchmark results, as described by Rudebusch and Svensson [36], this model also appears to roughly capture the views about the dynamics of the economy held by many monetary policymakers. The empirical fit of the model is also quite good compared, for example, to an unrestricted VAR. Indeed, the model can be interpreted as a restricted VAR, where the restrictions imposed are not at odds with the data as judged, for example, with standard model information criteria (see Rudebusch and Svensson [36]). ${ }^{6}$

Finally, the model appears to be stable over various subsamples - an important condition for drawing inference. With a backward-looking model, the Lucas Critique may apply with particular force, so it is important to gauge its historical importance with econometric stability tests (Oliner, Rudebusch, and Sichel [29]). For example, consider a stability test from Andrews [1]: the maximum value of the likelihood-ratio test statistic for structural stability over all possible breakpoints in the middle 70 percent of the sample. For our estimated inflation equation, the maximum likelihood-ratio test statistic is 10.89 (in 1972:3), while the 10 percent critical value is 14.31 (from Table 1 in Andrews [1]). Similarly, for the output equation, the maximum statistic is 11.51 (in 1982:4), while the 10 percent critical value is 12.27 .

\footnotetext{
${ }^{4}$ The estimates are slightly different from those in Rudebusch and Svensson [36] because of data revisions and a longer sample.

${ }^{5}$ Using reconstructed historical euro-area data, this model has been estimated by Peersman and Smets [33] and Taylor [49]. They have obtained coefficient estimates that are close to our U.S. ones, although with lower inflation persistence.

${ }^{6}$ Söderström [39] scrutinizes the Rudebusch-Svensson model further.
} 


\subsection{Adding money to the model}

Money could be added to the aggregate supply and demand model described above in a variety of ways. Just as for our selection of equations (2.1) and (2.2), three considerations motivate our choice of a model with money: simplicity, congruence with actual central bank models, and empirical fit to the data. Perhaps most importantly, we add money to the model not as a "straw man", but in a fashion consistent with the views of monetary policymakers. ${ }^{7}$ As a general characterization, central bankers typically hold the view that movements in the monetary aggregates play essentially no role in the direct quarter-by-quarter determination of either output or prices; however, a sizable fraction also concedes that money may have some value as an indicator of economic developments (e.g., Meyer [26]).

This view of the role of monetary aggregates is evident in most central bank empirical policy models. For example, Smets [37] surveys the central bank models from 12 different countries (including 6 of the countries in the euro area) and notes:

In most of the central banks' macroeconometric models the transmission mechanism of monetary policy is modelled as an interest rate transmission process. The central bank sets the short-term interest rate, which influences interest rates over the whole maturity spectrum, other asset prices, and the exchange rate. These changes in financial variables then affect output and prices through the different spending components. The role of money is in most cases a passive one, in the sense that money is demand determined. [37, p. 226]

Our model will incorporate money in an identical fashion. The alternative, where money plays a direct role in output or inflation determination separate from interest rates, has little support among central banks or in the data. ${ }^{8}$ For example, Gerlach and Smets [13] fit small (output, inflation, and interest rate) VARs to each of the G7 countries and state: "In preliminary work we incorporated monetary aggregates (M3 or M2) in the analysis, but found that they appear largely determined by money demand shocks that in turn have little, if any, impact on the economy" (p. 191). Similarly, in our AD-AS structural model, lags of money (in levels or growth rates) were invariably insignificant when added to equations (2.1) and (2.2).

\footnotetext{
${ }^{7}$ Our analysis of money will be most convincing to central bankers (including those in the Eurosystem, who are, of course, among the most important ultimate consumers of this research) if using a model that is similar to the ones actually employed.

${ }^{8}$ There are two primary channels for the quantity of money to affect aggregate demand directly: a real balance effect and a bank lending channel. The lack of U.S. evidence for either of these two channels is noted in, respectively, Reifschneider, et al. [32] and Oliner and Rudebusch [28]. Meltzer [24] and Nelson [27] find evidence of an effect of real money on aggregate demand; the latter interprets this as a proxy for an effect via a long interest rate. The weak contribution of money in predicting inflation is described in Estrella and Mishkin [11] and Stock and Watson [40].
} 
Probably the most important exception to this general lack of interest in incorporating money directly into an AD-AS model is the $P^{*}$ model of Hallman, Porter, and Small [17]. This model, which is still only rarely used, has been estimated with reconstructed euro-area data in Gerlach and Svensson [14]. Results with an alternative $P^{*}$ inflation equation will be examined separately in subsection 3.3 below.

Instead, following the mainstream, we add money to our model with a separate moneydemand equation, which is cast in a standard error-correction form. The long-run money-demand function is

$$
m_{t}=q_{t}-\kappa_{i} i_{t}
$$

where $m_{t}$ is the $\log$ of real M2 (scaled by 100), i.e., $100 \ln \frac{M 2_{t}}{P_{t}}$. In the long run, the demand for real money moves one-for-one with real output ${ }^{9}$ and negatively with respect to the interest rate (a proxy for the opportunity cost of mone $^{10}$ ), so $\kappa_{i}$, the long-run interest rate semielasticity, is positive. The short-run money-demand equation takes the form

$$
\Delta m_{t+1}=-\kappa_{m}\left(m_{t}-q_{t}+\kappa_{i} i_{t}\right)+\kappa_{1} \Delta m_{t}+\xi_{t+1}
$$

where $\Delta m_{t+1} \equiv m_{t+1}-m_{t}$ is the growth rate of real money measured in percent per quarter, and $\xi_{t}$ is an iid shock with variance $\sigma_{\xi}^{2}$. Assuming that the stock of real money adjusts to its long run average, $q_{t}-\kappa_{i} i_{t}$, the error-correction coefficient $\kappa_{m}$ should be positive.

Before providing estimates of the money demand equation, it is instructive to examine the long-run equilibrium condition (2.5). Figure 2.1 shows the log of M2 velocity (that is, $v_{t} \equiv$ $\left.q_{t}-m_{t}\right)$ and the interest rate $\left(i_{t}\right)$. According to condition (2.5), these two variables should move together so that their difference is stationary. For most of the sample, this clearly appears to be the case (and, for example, Hallman, Porter and Small [17] provide supporting statistical evidence). In the 1990's, however, there was a dramatic increase in velocity, and the historical long-run relationship obviously broke down. The cause of this upward shift in velocity is still debated, but it is likely linked to the increased availability and liquidity of bond and stock

\footnotetext{
${ }^{9}$ When tested, we could not reject a unitary income elasticity (the p-value is .16), so it is imposed. This is consistent with previous empirical investigations such as Feldstein and Stock [12] and Porter and Small [31].

${ }^{10}$ Models of money with more institutional detail calculate the opportunity cost as the difference between the alternative rate for assets that are substitutes to money and the own-rate on money deposits. In the U.S., the alternative rate is typically a short-term rate like a 3-month Treasury bill rate, and the own-rate is the average rate on deposits in money market deposit accounts, small time deposit accounts, and so forth (e.g., Porter and Small [31]). However, since deposit rates are quite sluggish, much of the variation in such an opportunity cost can be captured with just the alternative rate, which, in our case, is proxied by the funds rate. (See, for example, figure 3 in Porter and Small [31].) In contrast, some studies employ the short rate as the own rate and a long-term market interest rate as the alternative rate (e.g., Hamburger [18]). However, simply enlarging our structural model to include a rational expectations model of the long-term yield is likely insufficient (see Hess, Jones, and Porter [19]), and modeling the relevant term premia are well beyond the scope of our investigation.
} 
Figure 2.1: M2 velocity and federal funds rate

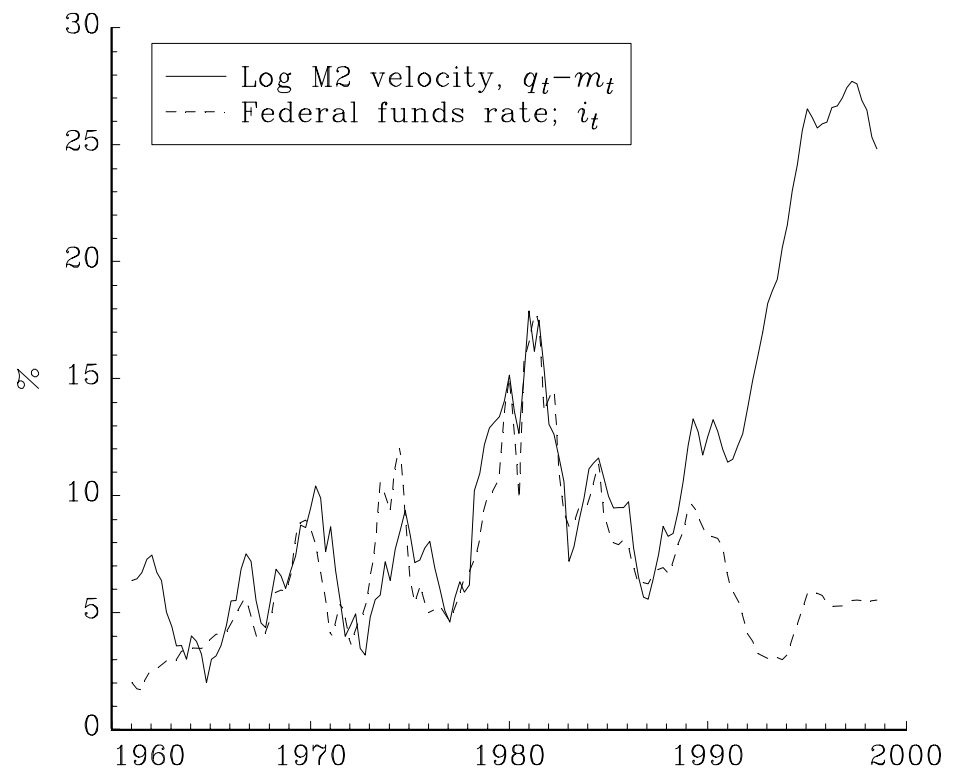

mutual funds. These factors may have triggered a significantly larger role for such mutual funds in household portfolio choice and as a payment vehicle. ${ }^{11}$

In any case, we estimate a money demand equation just over the relatively stable three decades before 1991, and our subsequent rule evaluations are based on this equation (along with (2.3) and (2.4)). We restrict the money demand sample because the 1990's may reflect special conditions in the evolution of U.S. financial institutions that are not relevant for Europe. Thus, our analysis (and any implications for the Eurosystem) assumes a stable money demand relationship like the one experienced by the U.S. before 1991. However, the following caveat must be stressed: given the potential for large structural shifts in Europe, especially after the shift to a monetary union, our results, which ignore the structural shift in money demand that has already occurred in the U.S., will clearly put money-growth targeting in a favorable light.

We estimate the long- and short-run money demand equations jointly in (2.6). The resulting equation estimated over the sample 1961:Q1 to 1990:Q4 is

$$
\begin{aligned}
\Delta m_{t+1}=- & .108\left(m_{t}-q_{t}\right)-\underset{(.037)}{\left..135 i_{t}+.635\right)} \\
& \overline{\mathrm{R}}^{2}=.51, \quad \mathrm{SE}=0.701, \mathrm{DW}=1.79
\end{aligned}
$$

Compared with other structural estimates of money demand in the literature, (2.7) appears

\footnotetext{
11 See discussion by Mehra [25] and Orphanides and Porter [30].
} 
to be a simple but reasonable representation. ${ }^{12}$ The value of the error correction coefficient $\left(\kappa_{m}\right)$ indicates that about 11 percent of the gap from the long-run equilibrium is closed each quarter. This is essentially the same convergence rate estimated in Mehra [25] and in Porter and Small [31] in much larger and more detailed money demand models. In addition, these authors provide estimates of the dynamic responses and the interest rate semi-elasticity of money that are also quite close to our own $\left(\kappa_{i}=1.25\right)$ (after accounting for our scaling of $\left.m_{t}\right)$.

Finally, as noted above, structural stability is an important condition for policy inference. Given the spectacular failures that have littered this field (e.g., the collapse of the Baba, Hendry, and Starr [3] model described in Hess, Jones, and Porter [19]), we only humbly note that over our shortened sample, the stability of our money demand equation is not rejected by the Andrews test (described above). Specifically, the maximum value of the likelihood-ratio test statistic for structural stability over all possible breakpoints is 9.91 (in 1981:1), while the 10 percent critical value is 12.27 (from Table 1 in Andrews [1]).

\subsection{The loss function and the optimal policy}

Thus, equations (2.1), (2.2), and (2.6) provide the aggregate supply, aggregate demand, and money-demand equations of the empirical model of the U.S. economy. To complete the model, we specify the relationship among output, the output gap, and potential output,

$$
y_{t} \equiv q_{t}-q_{t}^{*}
$$

and make the assumption that potential output is a random walk,

$$
q_{t+1}^{*}=q_{t}^{*}+\theta_{t+1},
$$

where $\theta_{t+1}$ is an iid shock with variance $\sigma_{\theta}^{2}$ and mean $\mu_{\theta}$ representing the upward growth of the economy.

We furthermore specify a loss function that allows us to compare inflation targeting and money-growth targeting in a convenient way. We assume that the relevant target variable under money-growth targeting is the four-quarter money growth rate, $\mu_{t}$, defined as

$$
\mu_{t} \equiv\left(m_{t}+p_{t}\right)-\left(m_{t-4}+p_{t-4}\right)=m_{t}-m_{t-4}+\bar{\pi}_{t}
$$

\footnotetext{
12 Estimates of such error correction money demand equations using reconstructed historical euro-area aggregates are surveyed in Browne, Fagan and Henry [5]. The associated coefficients estimates appear to be broadly in line to our U.S. estimates.
} 
(recall that $m_{t}$ is $(\log )$ real money). For convenience we set the inflation target and the moneygrowth targets to zero, so $\pi_{t}, \bar{\pi}_{t}$ and $\mu_{t}$ can be interpreted as deviations from the target. We then assume the loss function

$$
\lambda_{\pi} \operatorname{Var}\left[\bar{\pi}_{t}\right]+\lambda_{y} \operatorname{Var}\left[y_{t}\right]+\lambda_{\mu} \operatorname{Var}\left[\mu_{t}\right]+\lambda_{\Delta i} \operatorname{Var}\left[i_{t}-i_{t-1}\right]
$$

where the parameters $\lambda_{\pi}, \lambda_{y}, \lambda_{\mu}, \lambda_{\Delta i} \geq 0$ are the weights on inflation stabilization around the inflation target, output-gap stabilization, money-growth stabilization around the money-growth target, and interest-rate smoothing, respectively. We normalize the weights to sum to one. Throughout, we assume the weight $\lambda_{\Delta i}=0.2$, which corresponds to the standard weight on interest-rate smoothing in Rudebusch and Svensson [36]. Given the weight on interest-rate smoothing, we here define flexible inflation targeting (FIT) as $\lambda_{\pi}=\lambda_{y}=0.4, \lambda_{\mu}=0$; strict inflation targeting (SIT) as $\lambda_{\pi}=0.8, \lambda_{y}=\lambda_{\mu}=0$; strict output-gap targeting (SOT) as $\lambda_{y}=0.8$, $\lambda_{\pi}=\lambda_{\mu}=0$; and strict money-growth targeting (SMT) as $\lambda_{\mu}=0.8, \lambda_{\pi}=\lambda_{y}=0 .{ }^{13}$ Flexible inflation targeting corresponds to the standard case examined in Rudebusch and Svensson [36]. ${ }^{14}$

Minimizing the loss function (2.11) for given weights and the model (2.1), (2.2) and (2.6)(2.10), results in an optimal reaction function

$$
i_{t}=f X_{t},
$$

where $f$ is a row vector and $X_{t}$ is a vector of the state variables. Then the variances of the goal variables are easily calculated. ${ }^{15}$ By varying the weights, we can calculate the reaction function and the variances of the goal variables for each targeting case. We use the empirical parameters of (2.1), (2.2) and (2.6), with $\sigma_{\varepsilon}=1.08, \sigma_{\eta}=0.82$ and $\sigma_{\xi}=0.70$. The actual $\sigma_{\theta}$ for our potential output series is equal to 0.19 ; however, this series is essentially a segmented deterministic trend with infrequent breaks; thus, we set $\sigma_{\theta}$ equal to zero, which we interpret as corresponding to a fixed trend. ${ }^{16}$

\section{The efficiency frontier and monetary targeting for the U.S.}

Figure 3.1 summarizes the results on the efficiency frontier for inflation and output-gap variances for the different targeting cases $\left(\pi^{\mathrm{b}}\right.$ in the figure denotes $\left.\bar{\pi}\right)$. The solid line shows the efficiency

\footnotetext{
13 Note that, as dicussed in Rudebusch and Svensson [36], we use the term "targeting" to refer to the minimization of a loss function over expected future deviations of the target variable from a desired level.

${ }_{14}$ Rudebusch and Svensson [36] use the weights $\lambda_{\pi}=\lambda_{y}=1$ and $\lambda_{\nu}=0.5$ in their standard case.

15 An appendix available at the authors' websites provides technical details.

16 Smets [38] generalizes our model to allow for a stochastic trend in potential output, and he obtains an estimate of $\sigma_{\theta}=0.73$. Our results were robust to variation in $\sigma_{\theta}$.
} 
Figure 3.1: Variance tradeoffs for $\bar{\pi}_{t}$ and $y_{t}$

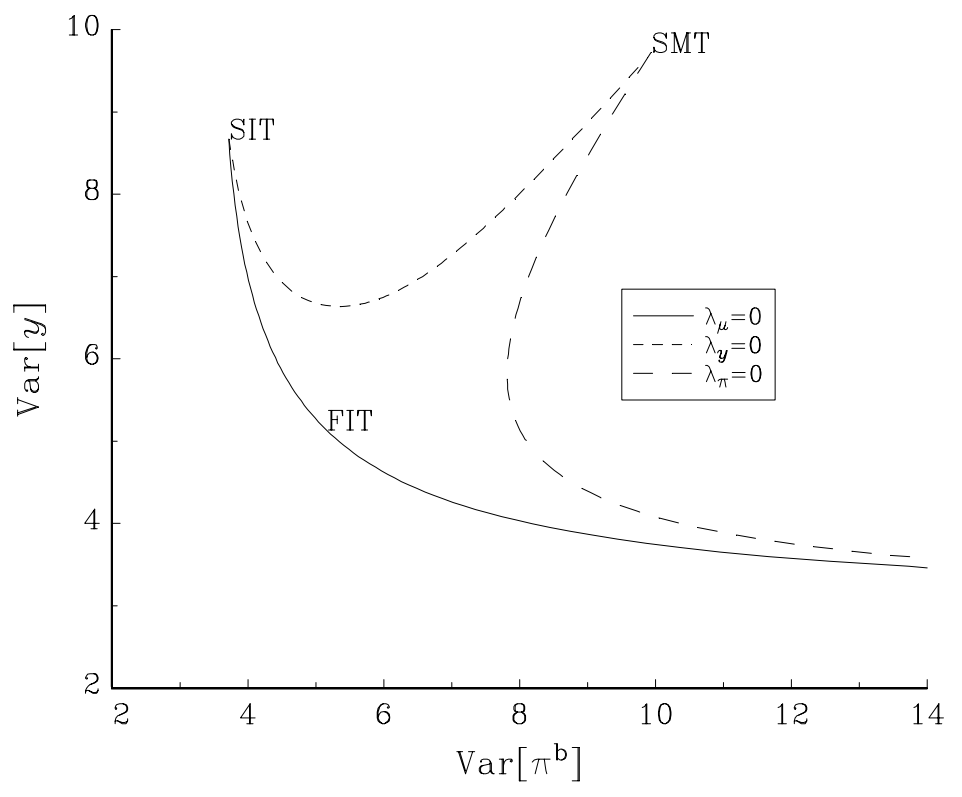

frontier, the best tradeoff between inflation variance and output-gap variance (given $\lambda_{\Delta i}=0.2$ ). It is generated by setting $\lambda_{\mu}=0$, letting $\lambda_{\pi}=.8-\lambda_{y}$, and letting $\lambda_{y}$ run from 0 to .8 , in which case $\lambda_{\pi}$ runs from .8 to 0 . The point SIT corresponds to strict inflation targeting $\left(\lambda_{\pi}=.8\right.$, $\left.\lambda_{y}=0\right)$. Point FIT, flexible inflation targeting, corresponds to $\lambda_{\pi}=\lambda_{y}=.4$, the standard case examined in Rudebusch and Svensson [36]. Strict output targeting $\left(\lambda_{\pi}=0, \lambda_{y}=.8\right)$ leads to a very high inflation variance, and the corresponding point SOT is far to the right outside the figure.

The line with short dashes corresponds to cases of mixed inflation and money-growth targeting, that is, when $\lambda_{y}=0, \lambda_{\pi}=.8-\lambda_{\mu}$ and $\lambda_{\mu}$ runs from 0 to .8 , in which case $\lambda_{\pi}$ runs from .8 to 0 . The point SMT corresponds to strict monetary targeting, when $\lambda_{\mu}=.8$ and $\lambda_{\pi}=\lambda_{y}=0$. The line with long dashes corresponds to cases of mixed money-growth and output-gap targeting, with $\lambda_{\pi}=0, \lambda_{\mu}=.8-\lambda_{y}$ and $\lambda_{y}$ running from 0 to .8 , in which case $\lambda_{\mu}$ runs from .8 to 0 .

It follows that for intermediate weights on inflation stabilization, output-gap stabilization, and money-growth stabilization, the corresponding combination of inflation and output-gap variance will be in the interior of the area enclosed by the three curves in figure 3.1. Thus, when there is some positive weight on money-growth stabilization, the resulting combination of inflation and output-gap variability will be inefficient. 
Table 1. Variances and losses

\begin{tabular}{lcccc|cccccc|c}
\hline Case & $\lambda_{\pi}$ & $\lambda_{y}$ & $\lambda_{\mu}$ & $\lambda_{g}$ & $\operatorname{Var} \bar{\pi}_{t}$ & $\operatorname{Var} y_{t}$ & $\operatorname{Var} \mu_{t}$ & $\operatorname{Var} \Delta i_{t}$ & Var $\Delta_{4} m_{t}$ & Var $g_{t}$ & Loss \\
\hline 1. FIT & .4 & .4 & 0 & 0 & 5.14 & 5.14 & 18.68 & 3.15 & 19.92 & 7.99 & 4.74 \\
2. SIT & .8 & 0 & 0 & 0 & 3.71 & 8.67 & 34.11 & 4.45 & 43.51 & 6.93 & 5.84 \\
3. SOT & 0 & .8 & 0 & 0 & 46499 & 2.90 & 46506 & 1.61 & 8.92 & 46502 & 18601 \\
4. SMT & 0 & 0 & .8 & 0 & 9.93 & 9.72 & 8.00 & 5.06 & 12.32 & 9.29 & 8.87 \\
5. SMTN & 0 & 0 & .8 & 0 & 9.72 & 9.34 & 5.24 & 1.92 & 9.46 & 9.01 & 8.01 \\
6. NGT & 0 & 0 & 0 & .8 & 9.08 & 23.03 & 39.70 & 3.76 & 70.89 & 4.66 & 13.60 \\
\hline
\end{tabular}

Note: For all cases, $\lambda_{\Delta i}=.2$. For case 5, SMTN refers to nonstochastic money demand, that is, $\sigma_{\xi}=0$.

The first four rows in table 1 report the weights and variances, including the variances of money growth and of the first-difference of the federal funds rate, for the four targeting cases discussed (disregard the last two rows and the columns for $\lambda_{g}$, Var $\Delta_{4} m_{t}$ and $\operatorname{Var} g_{t}$ for the time being). The last column reports the loss evaluated at the weights for flexible inflation targeting $\left(\lambda_{\pi}=\lambda_{y}=.4, \lambda_{\Delta i}=.2\right)$.

\subsection{Reasons for the inefficiency of money-growth targeting}

As we can see from figure 3.1 and table 1 , strict monetary targeting is quite inefficient, in the sense of incurring as high an output-gap variance as strict inflation targeting but causing much higher inflation variance. The loss evaluated at the standard weights is almost double the one of flexible inflation targeting. What is the reason for this inefficiency?

The conventional wisdom is that money-growth targeting will be efficient if money demand is stable and inefficient when money demand is unstable. According to conventional wisdom, with stable money demand, there would be a stable relation between money and prices, and stable money growth would imply stable inflation. Conversely, with unstable money demand, there would not be a stable relation between money, and stable money growth would not imply stable inflation.

The conventional wisdom has been challenged by Svensson [41], [42] and [44], with the argument that the reaction function for the interest rate following from money-growth targeting is quite different from the optimal reaction function under inflation targeting and therefore likely to be inefficient. In particular, the reaction function is also quite different under the assumption of a completely nonstochastic money demand without any money-demand shocks. The present empirical model with its empirical money-demand function allows us to examine these issues.

The reaction function following from flexible inflation targeting, point FIT in figure 3.1 and 
row 1 in table 3 , is

$$
i_{t}=.86 \pi_{t}+.31 \pi_{t-1}+.37 \pi_{t-2}+.12 \pi_{t-3}+1.34 y_{t}-.35 y_{t-1}+.50 i_{t-1}-.06 i_{t-2}-.03 i_{t-3}
$$

In contrast, the reaction function resulting from strict money-growth targeting, point SMT in figure 2.1 and row 2 in table 1 , is

$$
\begin{aligned}
i_{t}= & .88 \pi_{t}+.32 \pi_{t-1}+.37 \pi_{t-2}+.10 \pi_{t-3}+.97 y_{t}-.16 y_{t-1}+.33 i_{t-1}-.02 i_{t-2}-.01 i_{t-3} \\
& +1.83 m_{t}-1.52 m_{t-1}-.31 m_{t-2}-.19 m_{t-3}+.18 q_{t}^{*} .
\end{aligned}
$$

The reaction function for monetary targeting is clearly quite different from the reaction function under flexible inflation targeting, in that the interest rate in the latter case depends (with sizeable coefficients) on current and lagged real money stocks. ${ }^{17}$

Is this difference in reaction functions sufficient to make money-growth targeting inefficient for a nonstochastic money-demand function (that is, without money-demand shocks) as well? We can examine this by setting the variance of the money-demand shocks equal to zero, $\sigma_{\xi}^{2}=0$. The result of strict money-growth targeting with nonstochastic money demand is shown in row 5 in table 1 and can be compared to row 4, with money-demand shocks. Whereas the variance of money growth is substantially lower without money-demand shocks, ${ }^{18}$ the variances of inflation and the output gap - as well as the overall loss - are only slightly lower in row 5 with a nonstochastic money demand than in row 4. It follows that the point SMT would only shift slightly to the southwest in figure 3.1, so that the figure would look very similar with nonstochastic money demand. Thus, the inefficiency of monetary targeting is not due to the instability of money demand. Instead, it is due to the form of the dynamic money-demand function and the resulting reaction function. ${ }^{19}$

That money-growth targeting does not imply low and stable inflation is further illustrated in figure 3.2. The solid curve shows the substantial tradeoff between inflation variability and money-growth variability. It corresponds to the curve with short dashes in figure 3.1 that shows cases of mixed inflation targeting and money-growth targeting (that is, when $\lambda_{y}=0$, $\lambda_{\pi}=.8-\lambda_{\mu}$ and $\lambda_{\mu}$ runs from 0 to .8). The dashed curve in figure 3.2 shows the same tradeoff

\footnotetext{
${ }^{17}$ Taylor [47] observes that money-growth targeting would imply a particular reaction function. He concludes, however, that the reaction would not differ too much from the Taylor rule, in that it would make the interest rate a function of inflation and output. However, as we can see, the reaction function under monetary targeting is actually quite different from the Taylor rule, in its dependence on current and lagged real money stocks.

${ }^{18}$ Readers may wonder why the variance of money growth is not zero under strict monetary targeting with a stable money demand. The reasons are two-fold. First, it is the demand for real money that is stable, so nominal money growth still varies with inflation. Second, the weight on interest-rate smoothing implies that money growth is stabilized somewhat less than what is feasible.

${ }_{19}$ The structure of the reaction function is further examined in an appendix available at the authors' websites.
} 
Figure 3.2: Variance tradeoffs for $\bar{\pi}_{t}$ and $\mu_{t}$

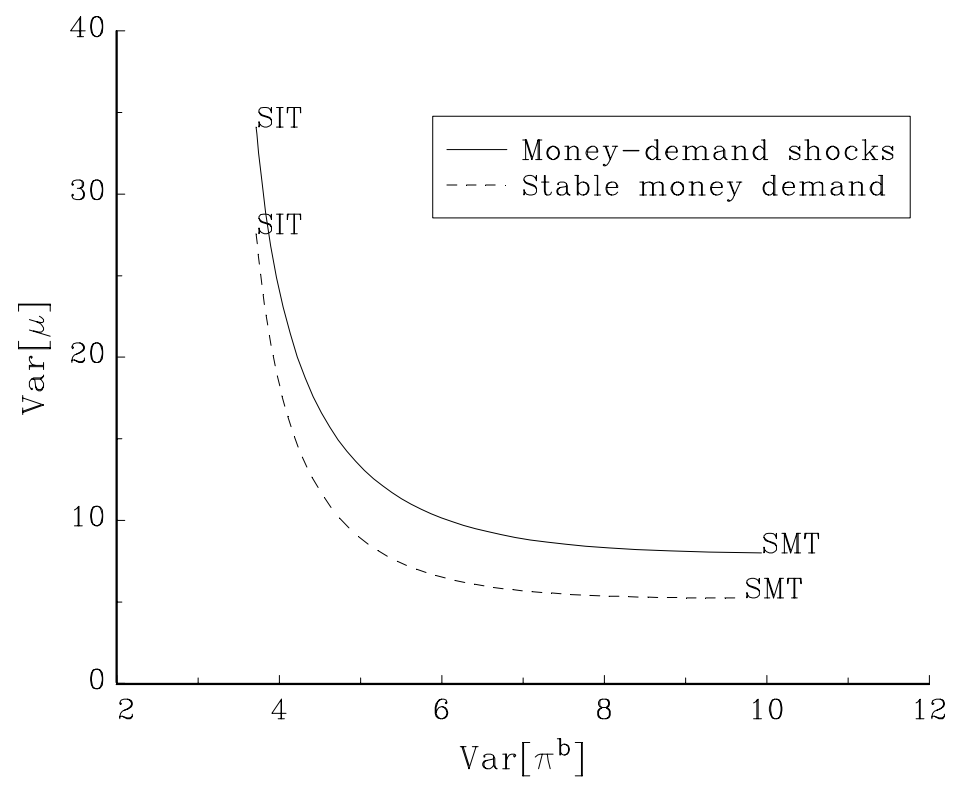

with nonstochastic money demand $\left(\sigma_{\xi}=0\right)$. The variability of money-growth is less, but there is still a substantial tradeoff and, as we have seen above, strict money-growth targeting still causes a high inflation variance.

Finally, the most direct intuition for why money-growth targeting does not stabilize inflation follows from the identity (2.10), rewritten as

$$
\bar{\pi}_{t} \equiv \mu_{t}-\Delta_{4} m_{t}
$$

where $\Delta_{4} m_{t} \equiv m_{t}-m_{t-4}$ is four-quarter real money growth. If the variance of real money growth $\Delta_{4} m_{t}$ were small, stable money growth $\mu_{t}$ would imply stable inflation $\bar{\pi}_{t}$. However, with an empirical money-demand function like (2.6), the variance of real money growth is far from small, as the column for Var $\Delta_{4} m_{t}$ in table 1 shows. Even with a nonstochastic moneydemand function, row 5, money-growth targeting implies a substantial variability in real money growth and hence in inflation.

\subsection{Nominal GDP targeting}

Nominal GDP targeting has been promoted by Gordon [15] and McCallum [21] and [22]. We can easily examine nominal GDP targeting in the present framework. ${ }^{20}$ Let us assume that the

\footnotetext{
${ }^{20}$ The required modifications of the model are detailed in an appendix at the authors' websites.For an analysis of rules that respond to nominal output growth (rather than nominal output targeting), see Rudebusch [35].
} 
relevant target variable is four-quarter nominal GDP growth, $g_{t}$, defined as

$$
g_{t} \equiv\left(p_{t}+q_{t}\right)-\left(p_{t-4}+q_{t-4}\right)=\bar{\pi}_{t}+q_{t}-q_{t-4} .
$$

We can then add the term $\lambda_{g} \operatorname{Var}\left[g_{t}\right]$ to the loss function (2.11), and represent nominal-GDPgrowth targeting (NGT) by $\lambda_{g}=0.8$ and $\lambda_{\Delta i}=0.2$.

The column for $\operatorname{Var}\left[g_{t}\right]$ in table 1 reports the variance of nominal-GDP growth for all the targeting cases. Row 6 reports the variances for nominal-GDP-growth targeting. Naturally, the variance of nominal-GDP growth is then the lowest. We see that the variance of inflation is high, and that the variance of the output gap is particularly high. The corresponding point NGT is far to the right outside figure 3.1.

Thus, nominal-GDP-growth targeting would be a very inefficient policy, even worse than strict money-growth targeting. The reason for this inefficiency is apparently the one pointed out by Ball [4] and further discussed in Svensson [43, Working Paper version], McCallum [23], Dennis [9] and Guender [16]. Since monetary policy affects output with a shorter lag than for inflation, nominal-GDP growth can be stabilized by output adjustments at a relatively short horizon when inflation is predetermined. These output adjustments, in turn, lead to high variability of inflation, which then requires even higher output variability in order to stabilize nominal-GDP growth. Only a positive weight on interest-rate smoothing prevents complete instability.

\subsection{An alternative $\mathbf{P}^{*}$ model of inflation}

The model used above, which has no direct role for money in the determination of output or inflation, does have the advantage of capturing to some approximation the views of many central bankers, including those at the ECB. In particular, although the ECB has no current official model, many researchers at the ECB and elsewhere use a model similar to the one above (e.g., Coenen and Wieland [6] and Peersman and Smets [33]).) As noted above, these views are shaped by the data. It is very difficult to find significant, stable, direct effects of money on the economy. For example, even over the short sample from 1961 to 1990, including several lags of quarterly money growth make no significant contribution to explaining inflation.

An alternative model with money that appears to have some empirical success is the $P^{*}$ model of inflation of Hallman, Porter, and Small [17] (see Svensson [46] for a recent discussion):

$$
\pi_{t+1}=\tilde{\alpha}_{\pi 1} \pi_{t}+\tilde{\alpha}_{\pi 2} \pi_{t-1}+\tilde{\alpha}_{\pi 3} \pi_{t-2}+\tilde{\alpha}_{\pi 4} \pi_{t-3}-\alpha_{p}\left(p_{t}-p_{t}^{*}\right)+\varepsilon_{t+1},
$$


where $p_{t}^{*} \equiv m_{t}+v_{t}^{*}-q_{t}^{*}$ is the long-run equilibrium price level and $v_{t}^{*}$ is the long-run equilibrium value of $(\log )$ velocity (that is, resulting from output equal to potential output and the interest rate equal to its long-run equilibrium value). As noted above, for the 1960 to 1990 period in the U.S., velocity is stationary, so $v_{t}^{*}$ is a constant, $v^{*}$. The rationale for the $P^{*}$ model is that in a stable long-run equilibrium where output grows at potential and velocity has stabilized at its equilibrium, the quantity equation indicates that the aggregate price level must equal $p_{t}^{*}$.

There are two transformations of the price gap that help illuminate the relationship of the $P^{*}$ equation (3.2) to the Phillips curve (2.1). First, as noted in Hallman, Porter, and Small [17], $-\left(p_{t}-p_{t}^{*}\right)=\left(q_{t}-q_{t}^{*}\right)-\left(v_{t}-v^{*}\right)$. Thus, if velocity remains fairly close to its long-run equilibrium value, the negative of price gap matches the output gap and the $P^{*}$ model reduces to a standard Phillips curve in terms of the output gap. As shown in figure 2.1, velocity remained relatively close to its long-run average except during the 1990s. The 1990s therefore provide a test of the relative value of the Phillips curve and $P^{*}$ models, and, as discussed below, it is a test that the $P^{*}$ model fails. A second interesting transformation of the price gap (noted in Whitesell [50] and Svensson [46]) is $-\left(p_{t}-p_{t}^{*}\right)=m_{t}-q_{t}^{*}+v^{*} \equiv m_{t}-m_{t}^{*}$, where $m_{t}^{*} \equiv q_{t}^{*}-v_{t}^{*}$ is the long-run equilibrium real money stock; that is, the negative of the price gap equals a real money gap, $m_{t}-m_{t}^{*}$. Furthermore, note that in terms of an empirical regression analysis, since $v^{*}$ is a constant here, it is absorbed by the regression constant (or in our case by the de-meaning of the regression variables) and so plays no role in explaining movements in inflation. Thus, the empirical comparison between the Phillips curve and $P^{*}$ models depends on which quantity gap better predicts inflation: the output gap between $q_{t}$ and $q_{t}^{*}$ (i.e., $y_{t}$ ) or the real money gap between $m_{t}$ and $m_{t}^{*}$ (in this case between $m_{t}$ and $q_{t}^{*}$ ). Any difference between the two models hinges on whether real output relative to potential or real money relative to (that same) potential provides a better measure of the aggregate supply and demand imbalance that drives inflation.

These two quantity gaps are shown in figure 3.3. There is little quantitative difference between the output and real money gaps from 1961:Q1 to 1990:Q4 - their correlation is .77. Not surprisingly then, the $P^{*}$ model performs similarly to the Phillips curve during this sample:

$$
\begin{aligned}
& \pi_{t+1}=\underset{(.091)}{.720 \pi_{t}} \underset{(.111)}{.065 \pi_{t-1}}+\underset{(.111)}{.265 \pi_{t-2}}+\underset{(.089)}{.080 \pi_{t-3}}+\underset{(.020)}{.077\left(m_{t}-m_{t}^{*}\right)}+\varepsilon_{t+1}, \\
& \overline{\mathrm{R}}^{2}=.82, \quad \mathrm{SE}=1.064, \quad \mathrm{DW}=1.98
\end{aligned}
$$

Indeed, at the crude aggregate level that we are working at and over this short sample, there is 
Figure 3.3: The real money gap and the output gap

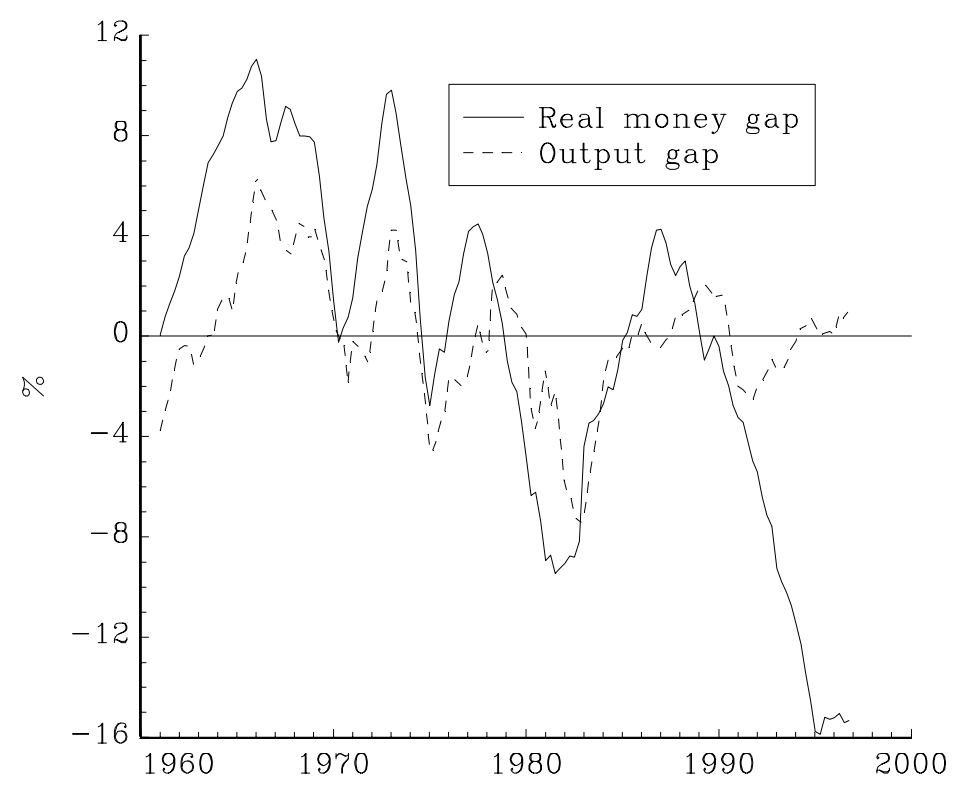

little to choose from empirically between (3.3) and (2.3). ${ }^{21}$ However, even over this short sample, there is some sign of structural instability in (3.3). The Andrews [1] maximum likelihood-ratio test statistic is 15.14 (in 1972:2), which is significant at the 10 percent critical value (although not the 5 percent level).

More seriously, the $P^{*}$ model displays much greater instability in the 1990s. After 1990, the output gap and the real money gap diverge greatly (their correlation in this subsample is -.94). However, it is not the case that the unique information in the real money gap better explained the behavior of inflation in the 1990s. In terms of predictive accuracy, using the short-sample estimates of the $P^{*}$ model in (3.3) to forecast inflation in the 1990s gives disastrous results (see, for instance, figure 6 of Orphanides and Porter [30]). The problem is that the U.S. long-run equilibrium level of velocity, $v^{*}$, apparently shifted in the 1990s in an unforecastable and, even now, a somewhat inexplicable fashion. Of course, it is always possible to define a $v^{*}$ such that the $P^{*}$ model fits the data; however, the key failing of the $P^{*}$ model for real-time forecasting and policy analysis is that it requires contemporaneous estimates of both $q_{t}^{*}$ and $v^{*}$. (For further discussion of real-time policy analysis, see Rudebusch [35] and Christiano [8].)

Still, as with our analysis of money demand above, we can limit ourselves to the short

\footnotetext{
${ }^{21}$ If both gaps are included in the short sample regression, they are jointly significant but individually insignificant. Note that on theoretical grounds, the original aggregate supply equation appears to us to be on a stronger foundation than the $P^{*}$ model.
} 
sample where the $P^{*}$ model performs well. This system, which represents an extreme best case scenario for supporting money targeting, comprises equations (3.3), (2.4), and (2.7). Despite the substantial monetary character of this model, as shown in table 2, a positive weight on moneygrowth stabilization results in an inefficient combination of inflation and output-gap variability, also for a nonstochastic money demand..$^{22}$

Table 2. Variances and losses in the $P^{*}$ model

\begin{tabular}{lcccc|cccccc|c}
\hline Case & $\lambda_{\pi}$ & $\lambda_{y}$ & $\lambda_{\mu}$ & $\lambda_{g}$ & $\operatorname{Var} \bar{\pi}_{t}$ & $\operatorname{Var} y_{t}$ & $\operatorname{Var} \mu_{t}$ & $\operatorname{Var} \Delta i_{t}$ & Var $\Delta_{4} m_{t}$ & Var $g_{t}$ & Loss \\
\hline 1. FIT & .4 & .4 & 0 & 0 & 3.42 & 3.56 & 10.61 & 1.42 & 12.91 & 7.40 & 3.08 \\
2. SMT & 0 & 0 & .8 & 0 & 19.26 & 16.43 & 2.95 & 4.36 & 20.95 & 16.93 & 15.15 \\
3. SMTN & 0 & 0 & .8 & 0 & 16.22 & 14.44 & 0.41 & 1.39 & 15.42 & 14.38 & 12.54 \\
\hline \multicolumn{7}{c}{ Note: For all cases, $\lambda_{\Delta i}=.2$. For case 3, SMTN refers to nonstochastic money demand, that is, $\sigma_{\xi}=0}$.
\end{tabular}

\section{Lessons for the Eurosystem}

\subsection{A lesson about money-growth targeting}

Above, we have shown in a simple empirical model that money-growth targeting can be quite inefficient, in the sense of inducing overly variable inflation or output. As noted in the introduction, the monetary policy strategy of the Eurosystem assigns a prominent role to money growth. In particular, the deviation of current M3 growth from a reference value is interpreted as an indicator of the risk to price stability. However, the Eurosystem has rejected monetary targeting, by emphasizing that money growth will not be an intermediate target to be brought in line with the reference value. Issing [20] is quite explicit on this:

$[T]$ he monetary policy strategy selected by the ESCB is not a variant of intermediate monetary targeting... Certain technical pre-conditions have to be met before a monetary targeting strategy is feasible. Specifically, an intermediate monetary target would only be a meaningful guide to monetary policy if a stable relationship existed between money and prices, and money was controllable in the short run using policy determined interest rates...

Future shifts in the velocity of money are certainly possible - perhaps even likely. They cannot be predicted with certainty. Moreover, it is not clear whether those aggregates that have the best results in terms of stability are sufficiently controllable in the short-term with the policy instruments available to the ESCB. In these circumstances, relying on a pure monetary targeting strategy would constitute an unrealistic, and therefore misguided, commitment.

\footnotetext{
${ }^{22}$ Gerlach and Svensson [14], although finding substantial empirical support for the real money gap as a predictor of future inflation, also find that the Eurosystem's nominal money-growth indicator is likely to be a poor indicator of future inflation.
} 
Thus, according to Issing, the Eurosystem has rejected monetary targeting for the Eurosystem, on the grounds that money demand is likely to be unstable and not sufficiently controllable. The implication seems to be that, if euro money demand had been found to be stable and sufficiently controllable, money-growth targeting would have been appropriate. Furthermore, if the Eurosystem would, in the future, find that money demand is stable and sufficiently controllable, money-growth targeting might be appropriate and the money-growth indicator might change status and become an intermediate target variable.

The empirical demand function for U.S. M2 that we have estimated is quite well-behaved. By excluding the period after 1991 from the sample, we obtain a relatively stable money-demand function with a good fit and small money-demand shocks. Furthermore, money is quite controllable in this equation, with a semielasticity of one-quarter-ahead real and nominal money with respect to the federal funds rate given by $\kappa_{m} \kappa_{i}=.135$. Nevertheless, even with this well-behaved money demand function, money-growth targeting would be very inefficient in the U.S. Even if we were to set the money-demand shocks equal to zero and make the money-demand equation completely nonstochastic, the efficiency of money-growth targeting would improve only slightly.

Similarly, if the euro-area economy can be reasonably well described by a system of equations not too dissimilar from our model (as argued in the introduction), we must conclude that money-growth targeting by the Eurosystem is likely to be quite inefficient, even under the extreme assumption of a completely nonstochastic money demand. Thus, one main lesson for the Eurosystem seems to be that it would be wise to continue rejecting money-growth targeting, regardless of whether the demand for euro M3 is nonstochastic or not, and regardless of how controllable it is.

\subsection{A lesson about the money-growth indicator}

Even though the Eurosystem has rejected money-growth targeting, it maintains that the moneygrowth indicator is a crucial indicator for its price-stability-oriented monetary policy. Indeed, since the money-growth indicator has been elevated to be one of the two "pillars" supporting Eurosystem monetary policy, the impression is that the Eurosystem will give it at least the same weight as its internal inflation forecasts. Svensson [44] and [45] has criticized the emphasis on the money-growth indicator and argued that it is likely to be a poor indicator of the risk to price stability. In effect, on theoretical grounds, it appears to mainly be a noisy indicator of current inflation, rather than a good predictor of future inflation at horizons relevant for 
monetary policy decisions.

Can we say anything about the likely performance of the money-growth indicator from the empirical model in the present paper? The issue boils down to how well money growth predicts future inflation. We examine this by calculating the correlation between money growth and two different inflation forecasts. ${ }^{23}$ First, we have the "unchanged-interest-rate" forecast of four-quarter inflation $T$ quarters ahead, denoted $\bar{\Pi}_{t+T \mid t}\left(i_{t-1}\right)$. This is the forecast conditional on an unchanged interest rate, $i_{t+\tau}=i_{t-1}$ for $\tau \geq 0$, and the current state of the economy. Svensson [44] argues that the best indicator of the risk to price stability is the deviation between an unchanged-interest-rate forecast and the inflation target. This indicator obviously signals by how much the inflation target is likely to be missed if there is no policy adjustment. It also signals the direction and the magnitude of the optimal instrument adjustment. Then, the correlation of current money growth with the unchanged-interest-rate forecast for different horizons should be a good measure of the performance of the money-growth indicator. Second, we have the "equilibrium" forecast of four-quarter inflation $T$ quarters ahead, denoted $\bar{\pi}_{t+T \mid t}$. This is the forecast conditional on the optimal reaction function (2.12) and the current state of the economy.

The correlation coefficients for the correlation of current monetary growth with unchangedinterest-rate and equilibrium inflation forecasts, $\operatorname{Corr}\left[\mu_{t}, \bar{\Pi}_{t+T \mid t}\left(i_{t-1}\right)\right]$ and $\operatorname{Corr}\left[\mu_{t}, \bar{\pi}_{t+T \mid t}\right]$, are reported in table 3 , for the case of flexible inflation targeting $\left(\lambda_{\pi}=\lambda_{y}=.4, \lambda_{\Delta i}=.2\right)$ and for different horizons $T .{ }^{24}$ We see that for longer horizons, the correlation is higher with unchangedinterest-rate inflation forecasts than for equilibrium forecasts. Still, the correlation is quite low and does not exceed .3. For horizons around 8 quarters, which are often referred to as most relevant for monetary policy, the correlation coefficients are as low as .13 or .16. We conclude that the money-growth indicator is indeed a poor indicator of risks to price stability.

Table 3. Correlations of money growth with inflation forecasts

\begin{tabular}{l|cccccc}
\hline \multirow{2}{*}{ Type of inflation forecast } & \multicolumn{5}{|c}{ Horizon (quarters) } \\
\cline { 2 - 7 } & 1 & 2 & 4 & 8 & 12 & 16 \\
\hline Unchanged-interest-rate forecast & .18 & .16 & .13 & .16 & .25 & .27 \\
Equilibrium forecast & .18 & .16 & .13 & .13 & .14 & .14 \\
\hline
\end{tabular}

This conclusion does not change, even if money demand is completely nonstochastic. The correlations for this case are reported in table 4. Although the correlation is naturally higher with nonstochastic money demand, the correlation coefficients still do not exceed .35.

\footnotetext{
${ }^{23}$ These two inflation forecasts are discussed in detail in Rudebusch and Svensson [36].

24 An appendix available at the authors' websites provides technical details.
} 
Table 4. Correlations of money growth with inflation forecasts, nonstochastic money demand

\begin{tabular}{l|cccccc}
\hline \multirow{2}{*}{ Type of inflation forecast } & \multicolumn{5}{|c}{ Horizon (quarters) } \\
\cline { 2 - 7 } & 1 & 2 & 4 & 8 & 12 & 16 \\
\hline Unchanged-interest-rate forecast & .22 & .20 & .17 & .20 & .32 & .33 \\
Equilibrium forecast & .22 & .20 & .16 & .16 & .17 & .18 \\
\hline
\end{tabular}

Thus, with regard to the properties of money growth in the euro area, the main lesson is that it is likely to be a rather inferior indicator of future inflation.

\section{Conclusions}

Using an empirical model of U.S. inflation, output and money, we compare the performance of monetary targeting relative to inflation targeting. We exclude the period after 1990, when M2 money demand displayed considerable instability, from the sample period for the moneydemand estimation. As a result, our estimated money-demand equation is quite well-behaved with moderate money-demand shocks and controllable money demand.

Nevertheless, our results unambiguously show that monetary targeting would be quite inefficient for the U.S., in the sense of bringing much higher variability of inflation and the output gap than inflation targeting. Furthermore, setting money-demand shocks equal to zero and thus assuming a completely nonstochastic money demand only marginally reduces the inefficiency of monetary targeting.

Thus, counter to conventional wisdom, our results indicate that monetary targeting is not mainly inefficient due to potential instability of money demand. Instead, the inefficiency of monetary targeting is connected to the properties of the reaction function or the central bank's instrument following from monetary targeting. The dynamics of money demand is such that the resulting reaction function is quite unsuitable for stabilizing inflation and the output gap, even if there are no shocks to money demand. ${ }^{25}$ Thus, as argued on theoretical grounds in Svensson [41], [42] and [44], the reasons for the poor performance of monetary targeting are deeper and more fundamental than the instability of money demand. In terms of the identity that inflation equals nominal money growth less real money growth, with an empirical moneydemand equation, nominal money-growth targeting does not stabilize real money growth and

\footnotetext{
${ }^{25}$ Of course, we have only scratched the surface in terms of an analysis of monetary policy under uncertainty. However, the recent literature (for instance, Rudebusch [34] and Söderström [39]) suggest that introducing simple parameter uncertainty (varying the coefficients within their standard error bands) has little effect. In addition, with regard to uncertainty about the real-time data, Amato and Swanson [2] show that money data are also subject to important revisions. Thus, it is not obvious that monetary targeting would be favored with such uncertainty.
} 
hence not inflation.

The lessons for the Eurosystem are obvious. Fortunately, the Eurosystem has rejected monetary targeting and emphasized that the deviation of money growth from the reference value is to be used as an indicator of risks to price stability rather than as an intermediate target variable. Nevertheless, the Eurosystem has given a prominent role to this indicator and elevated it to the status of one of two pillars supporting its monetary policy, the other pillar being the Eurosystem's internal inflation forecast. There seems to be no support for that elevation of the money-growth indicator. Our results indicate that the money-growth indicator has quite a low correlation with inflation forecasts, both unchanged-interest-rate and equilibrium forecasts. Therefore, money growth is likely to be a poor indicator of risks to price stability. This is even more problematic since the Eurosystem has announced that it will keep its internal inflation forecasts secret and use the money-growth indicator and the reference value as the main communicating device with the market and the general public. Instead of the money-growth being one of two pillars, it should rather, at most, be one brick among many in the construction of inflation and output-gap forecasts that will be the crucial input in its monetary policy decisions.

In passing, we have also shown that nominal-GDP targeting, in our empirical model of the U.S. economy, would be an even more inefficient policy than monetary targeting. Since monetary policy realistically affects output with a shorter lag than for inflation, nominal-GDP growth can be stabilized by output adjustments at a relatively short horizon, for which inflation is predetermined. These output adjustments, in turn, lead to high variability of inflation, which then requires even higher output variability in order to stabilize nominal-GDP growth. 


\section{References}

[1] Andrews, Donald W.K. (1993), "Tests for Parameter Instability and Structural Change with Unknown Change Point," Econometrica, 61(4), 821-856.

[2] Amato, Jeffery D. and Norman Swanson (1999), "The Real-Time (In)Significance of Money," manuscript, Bank for International Settlements.

[3] Baba, Y., David Hendry, and Ross Starr (1992), "The Demand for M1 in the U.S.A." Review of Economic Studies 59, 25-61.

[4] Ball, Laurence (1997), "Efficient Rules for Monetary Policy," NBER Working Paper No. 5952.

[5] Browne, F.X., G. Fagan and J. Henry (1997), "Money Demand in EU Countries: A Survey," Staff Paper No. 7, European Monetary Institute.

[6] Coenen, Günter, and Volker Wieland (2000), "A Small Estimated Euro Area Model with Rational Expectations and Nominal Rigidities," manuscript, European Central Bank.

[7] Congressional Budget Office (1995), "CBO's Method for Estimating Potential Output," CBO Memorandum, October 1995.

[8] Christiano, Lawrence J. (1989), " $P^{*}$ Is Not the Inflation Forecaster's Holy Grail," Quarterly Review 13, Federal Reserve Bank of Minneapolis, Fall, 3-18.

[9] Dennis, Richard (1998), "Instability Under Nominal GDP Targeting: The Role of Expectations," Working Paper, Australia National University.

[10] European Central Bank (1999), "Editorial," ECB Monthly Bulletin, January 1999, 9-10.

[11] Estrella, Arturo, and Frederic S. Mishkin (1997), "Is there a Role for Monetary Aggregates in the Conduct of Monetary Policy?" Journal of Monetary Economics 40, 279-304.

[12] Feldstein, Martin, and James H. Stock (1994), "The Use of a Monetary Aggregate to Target Nominal GDP," in N. Gregory Mankiw (ed.), Monetary Policy, University of Chicago Press (Chicago), 7-62. 
[13] Gerlach, Stefan, and Frank Smets (1995), "The Monetary Transmission Mechanism: Evidence from the G-7 Countries," in Financial Structure and the Monetary Policy Transmission Mechanism, Bank for International Settlements (Basle, Switzerland), 188-224.

[14] Gerlach, Stefan, and Lars E.O. Svensson (1999), "Money and Inflation in the Euro Area: A Case for Monetary Indicators?" Working Paper.

[15] Gordon, Robert J. (1985), "The Conduct of Monetary Policy," in A. Ando, H. Eguchi, R. Farmer and Y. Suzuki, eds., Monetary Policy in Our Times, MIT Press, Cambridge, MA, 45-81.

[16] Guender, Alfred V. (1998), "Nominal Income Targeting vs. Strict Inflation Targeting: A Comparison," Working Paper, University of Canterbury, Christchurch.

[17] Hallman, Jeffrey J., Richard D. Porter, and David H. Small, (1991), "Is the Price Level Tied to the M2 Monetary Aggregate in the Long Run?," American Economic Review 81, 841-858.

[18] Hamburger, M. (1977), "Behavior of the Money Stock: Is There a Puzzle?," Journal of Monetary Economics 3, 265-288.

[19] Hess, Gregory D., Christopher S. Jones, and Richard D. Porter, (1998), "The Predictive Failure of the Baba, Hendry, and Starr Model of M1," Journal of Economics and Business $50,477-507$.

[20] Issing, Otmar (1998), "The European Central Bank at the eve of EMU," speech in London, November 26, 1998.

[21] McCallum, Bennett T. (1988), "Robustness Properties of a Rule for Monetary Policy," Carnegie-Rochester Conference Series on Public Policy 29, 173-204.

[22] McCallum, Bennett T. (1997), "Issues in the Design of Monetary Policy Rules," NBER Working Paper No. 6016.

[23] McCallum, Bennett T. (1997b), "The Alleged Instability of Nominal Income Targeting." NBER Working Paper No. 6291.

[24] Meltzer, Allan H. (1999), "The Transmission Process," Working Paper, Carnegie-Mellon University. 
[25] Mehra, Yash P. (1997), "A Review of the Recent Behavoir of M2 Demand," Federal Reserve Bank of Richmond Economic Quarterly 83(3), 27-43.

[26] Meyer, Laurence H. (1997), "The Economic Outlook and Challenges for Monetary Policy," Remarks at the Charlotte Economics Club, Charlotte, North Carolina, January 16.

[27] Nelson, Edward (2000), "Direct Effects of Base Money on Aggregate Demand: Theory and Evidence," Working Paper, Bank of England.

[28] Oliner, Stephen D., and Glenn D. Rudebusch (1995), "Is There a Bank Lending Channel for Monetary Policy," Economic Review, Federal Reserve Bank of San Francisco, No. 2, $3-20$.

[29] Oliner, Stephen D., Glenn D. Rudebusch, and Daniel Sichel (1996), "The Lucas Critique Revisited: Assessing the Stability of Empirical Euler Equations for Investment," Journal of Econometrics 70, 291-316.

[30] Orphanides, Athanasios, and Richard Porter, (2000), "P* Revisited: Money-Based Inflation Forecasts with a Changing Equilibrium Velocity," Journal of Economics and Business 52, $87-100$.

[31] Porter, Richard, and David Small (1989), "Understanding the Behavior of M2 and V2," Federal Reserve Bulletin 75, 244-254.

[32] Reifschneider, David, Robert Tetlow, and John Williams (1999), "Aggregate Disturbances, Monetary Policy, and the Macroeconomy: The FRB/US Perspective," Federal Reserve Bulletin 85, 1-19.

[33] Peersman, Gert, and Frank Smets (1999), "Uncertainty and the Taylor Rule in a Simple Model of the Euro-Area Economy," Working Paper.

[34] Rudebusch, Glenn D. (1999), "Is the Fed Too Timid? Monetary Policy in an Uncertain World," Working Paper 99-05, Federal Reserve Bank of San Francisco.

[35] Rudebusch, Glenn D. (2000), "Assessing Nominal Income Rules for Monetary Policy with Model and Data Uncertainty,” Working Paper 2000-03, Federal Reserve Bank of San Francisco. 
[36] Rudebusch, Glenn D., and Lars E.O. Svensson (1999), "Policy Rules for Inflation Targeting," in Monetary Policy Rules, ed. by John B. Taylor, 203-246. Chicago: Chicago University Press.

[37] Smets, Frank (1995), "Central Bank Macroeconometric Models and the Monetary Policy Transmission Mechanism," in Financial Structure and the Monetary Policy Transmission Mechanism, Bank for International Settlements (Basle, Switzerland), 225-266.

[38] Smets, Frank (1999), "Output Gap Uncertainty: Does It Matter For the Taylor Rule?," In Monetary Policy under Uncertainty, eds. B. Hunt and A. Orr, pp. 10-29. Wellington: Reserve Bank of New Zealand.

[39] Söderström, Ulf (1999), "Should Central Banks Be More Agressive?" Working Paper, Stockholm School of Economics.

[40] Stock, James H., and Mark W. Watson (1999), "Forecasting Inflation," Journal of Monetary Economics 44, 293-335.

[41] Svensson, Lars E.O. (1997), "Inflation Forecast Targeting: Implementing and Monitoring Inflation Targets," European Economic Review 41, 1111-1146.

[42] Svensson, Lars E.O. (1999a), "Inflation Targeting as a Monetary Policy Rule," Journal of Monetary Economics 43, 607-654.

[43] Svensson, Lars E.O. (1999b), "Inflation Targeting: Some Extensions," Scandinavian Journal of Economics 101, 337-361.

[44] Svensson, Lars E.O. (1999c), "Monetary Policy Issues for the Eurosystem," CarnegieRochester Conference Series on Public Policy 51-1, 79-136.

[45] Svensson, Lars E.O. (1999d), "Price-Stability as Target for Monetary Policy: Defining and Maintaining Price Stability," in Deutsche Bundesbank, The Monetary Transmission Process: Recent Developments and Lessons for Europe, MacMillan, London, forthcoming.

[46] Svensson, Lars E.O. (2000), "Does the $P^{*}$ Model Provide Any Rationale for Monetary Targeting?" German Economic Review 1, 69-81.

[47] Taylor, John B. (1999a), "A Historical Analysis of Monetary Policy Rules". in Taylor [48]. 
[48] Taylor, John B., ed. (1999b), Monetary Policy Rules, Chicago University Press.

[49] Taylor, John B. (1999c), "The Robustness and Efficiency of Monetary Policy Rules as Guidelines for Interest Rate Setting by the European Central Bank," Journal of Monetary Economics 43, 655-679.

[50] Whitesell, William, (1997), "Interest Rates and M2 in an Error Correction Macro Model," Federal Reserve Board, FEDS Working Paper 1997-59. 


\section{Eurosystem Monetary Targeting: \\ Lessons from U.S. Data}

Glenn D. Rudebusch and Lars E.O. Svensson

Unpublished Technical Appendices

\section{A. The optimization problem}

For a discount factor $\delta, 0<\delta<1$, we consider the intertemporal loss function in quarter $t$,

$$
\mathrm{E}_{t}(1-\delta) \sum_{\tau=0}^{\infty} \delta^{\tau} L_{t+\tau}
$$

where the period loss function is

$$
L_{t}=\lambda_{\pi} \bar{\pi}_{t}^{2}+\lambda_{y} y_{t}^{2}+\lambda_{\mu} \mu_{t}^{2}+\lambda_{\Delta i}\left(i_{t}-i_{t-1}\right)^{2} .
$$

When $\delta \rightarrow 1$, the loss function (A.1) with (A.2) approaches $\mathrm{E}\left[L_{t}\right]$ which equals (2.11).

The model (2.1), (2.2) and (2.6)-(2.9) has a convenient state-space representation,

$$
X_{t+1}=A X_{t}+B i_{t}+u_{t+1}
$$

The $15 \times 1$ vector $X_{t}$ of state variables, the $15 \times 15$ matrix $A$, the $15 \times 1$ column vector $B$, and the $15 \times 1$ column disturbance vector $u_{t}$ are given by

$$
X_{t}=\left[\begin{array}{c}
\pi_{t} \\
\pi_{t-1} \\
\pi_{t-2} \\
\pi_{t-3} \\
y_{t} \\
y_{t-1} \\
i_{t-1} \\
i_{t-2} \\
i_{t-3} \\
m_{t} \\
m_{t-1} \\
m_{t-2} \\
m_{t-3} \\
m_{t-4} \\
q_{t}^{*}
\end{array}\right], A=\left[\begin{array}{c}
\sum_{j=1}^{4} \alpha_{\pi j} e_{j}+\alpha_{y} e_{5} \\
e_{1} \\
e_{2} \\
e_{3} \\
\beta_{r} e_{1: 4}+\beta_{y 1} e_{5}+\beta_{y 2} e_{6}-\beta_{r} e_{7: 9} \\
e_{5} \\
e_{0} \\
e_{7} \\
e_{8} \\
A_{10} \\
e_{10} \\
e_{11} \\
e_{12} \\
e_{13} \\
e_{15}
\end{array}\right], B=\left[\begin{array}{c}
0 \\
0 \\
0 \\
0 \\
-\beta_{r} / 4 \\
0 \\
1 \\
0 \\
0 \\
-\kappa_{m} \kappa_{i} \\
0 \\
0 \\
0 \\
0 \\
0
\end{array}\right], u_{t}=\left[\begin{array}{c}
\varepsilon_{t} \\
0 \\
0 \\
0 \\
\eta_{t} \\
0 \\
0 \\
0 \\
0 \\
\xi_{t} \\
0 \\
0 \\
0 \\
0 \\
\theta_{t}
\end{array}\right] ;
$$

where $A_{10}$, the 10 th row of the matrix $\mathrm{A}$, is given by

$$
A_{10}=\left(1-\kappa_{m}+\kappa_{1}\right) e_{10}-\kappa_{1} e_{11}+\kappa_{m}\left(e_{5}+e_{15}\right)
$$


$e_{j}(j=0,1, \ldots, 15)$ denotes a $1 \times 15$ row vector, for $j=0$ with all elements equal to zero, for $j=1, \ldots, 15$ with element $j$ equal to unity and all other elements equal to zero; and where $e_{j: k}$ $(j<k)$ denotes a $1 \times 15$ row vector with elements $j, j+1, \ldots, k$ equal to $\frac{1}{4}$ and all other elements equal to zero.

Furthermore, it is convenient to define the $4 \times 1$ vector $Y_{t}$ of goal variables. It fulfills

$$
Y_{t}=C_{X} X_{t}+C_{i} i_{t}
$$

where the vector $Y_{t}$, the $4 \times 15$ matrix $C_{X}$ and the $4 \times 1$ column vector $C_{i}$ are given by

$$
Y_{t}=\left[\begin{array}{c}
\bar{\pi}_{t} \\
y_{t} \\
\mu_{t} \\
i_{t}-i_{t-1}
\end{array}\right], C_{X}=\left[\begin{array}{c}
e_{1: 4} \\
e_{5} \\
e_{1: 4}+e_{10}-e_{14} \\
-e_{7}
\end{array}\right], C_{i}=\left[\begin{array}{l}
0 \\
0 \\
0 \\
1
\end{array}\right]
$$

Then, the period loss function can be written

$$
L_{t}=Y_{t}^{\prime} K Y_{t}
$$

where the $4 \times 4$ matrix $K$ has the diagonal $\left(\lambda_{\pi}, \lambda_{y}, \lambda_{\mu}, \lambda_{\Delta i}\right)$ and all its off-diagonal elements are equal to zero.

With (A.3), (A.1) and (A.2), the problem is written in a form convenient for the standard stochastic linear regulator problem (cf. Chow [1] and Sargent [2]). Minimizing (A.1) in each quarter, subject to (A.3) and the current state of the economy, $X_{t}$, results in a linear feedback rule for the instrument of the form (2.12). More precisely, the optimal instrument rule is the vector $f$ in (2.12) that fulfills

$$
f=-\left(R+\delta B^{\prime} V B\right)^{-1}\left(U^{\prime}+\delta B^{\prime} V A\right)
$$

where the $15 \times 15$ matrix $V$ fulfills the Riccati equation

$$
V=Q+U f+f^{\prime} U^{\prime}+f^{\prime} R f+\delta M^{\prime} V M
$$

where $M$ is the transition matrix given by (A.10) and $Q, U$ and $R$ are given by

$$
Q=C_{X}^{\prime} K C_{X}, U=C_{X}^{\prime} K C_{i}, R=C_{i}^{\prime} K C_{i}
$$

Furthermore, the optimal value of (A.1) is

$$
(1-\delta) X_{t}^{\prime} V X_{t}+\delta \operatorname{trace}\left(V \Sigma_{u u}\right)
$$


where $\Sigma_{u u}=\mathrm{E}\left[u_{t} u_{t}^{\prime}\right]$ is the covariance matrix of the disturbance vector. In the limit when $\delta$ approaches 1, the optimal rule converges to the one minimizing (2.11) and the optimal value of $(2.11)$ is

$$
\mathrm{E}\left[L_{t}\right]=\operatorname{trace}\left(V \Sigma_{u u}\right)
$$

For any reaction function of the form (2.12), the dynamics of the model follows

$$
\begin{aligned}
X_{t+1} & =M X_{t}+u_{t+1} \\
Y_{t} & =C X_{t},
\end{aligned}
$$

where the matrices $M$ and $C$ are given by

$$
\begin{aligned}
& M=A+B f \\
& C=C_{X}+C_{i} f .
\end{aligned}
$$

For any given reaction function $f$ resulting in finite unconditional variances of the goal variables, the unconditional loss (2.11) fulfills

$$
\mathrm{E}\left[L_{t}\right]=\mathrm{E}\left[Y_{t}^{\prime} K Y_{t}\right]=\operatorname{trace}\left(K \Sigma_{Y Y}\right)
$$

where $\Sigma_{Y Y}$ is the unconditional covariance matrix of the goal variables. ${ }^{26}$

The covariance matrix $\Sigma_{Y Y}$ for the goal variables is given by

$$
\Sigma_{Y Y} \equiv \mathrm{E}\left[Y_{t} Y_{t}^{\prime}\right]=C \Sigma_{X X} C^{\prime}
$$

where $\Sigma_{X X}$ is the unconditional covariance matrix of the state variables. The latter fulfills the matrix equation

$$
\Sigma_{X X} \equiv \mathrm{E}\left[X_{t} X_{t}^{\prime}\right]=M \Sigma_{X X} M^{\prime}+\Sigma_{u u}
$$

We can use the relations $\operatorname{vec}(A+B)=\operatorname{vec}(A)+\operatorname{vec}(B)$ and $\operatorname{vec}(A B C)=\left(C^{\prime} \otimes A\right) \operatorname{vec}(B)$ on (A.14) (where $\operatorname{vec}(A)$ denotes the vector of stacked column vectors of the matrix $A$, and $\otimes$ denotes the Kronecker product) which results in

$$
\begin{aligned}
\operatorname{vec}\left(\Sigma_{X X}\right) & =\operatorname{vec}\left(M \Sigma_{X X} M^{\prime}\right)+\operatorname{vec}\left(\Sigma_{u u}\right) \\
& =(M \otimes M) \operatorname{vec}\left(\Sigma_{X X}\right)+\operatorname{vec}\left(\Sigma_{u u}\right) .
\end{aligned}
$$

Solving for vec $\left(\Sigma_{X X}\right)$ we get

$$
\operatorname{vec}\left(\Sigma_{X X}\right)=[I-(M \otimes M)]^{-1} \operatorname{vec}\left(\Sigma_{u u}\right) .
$$

\footnotetext{
${ }^{26}$ The trace of a matrix $A, \operatorname{trace}(A)$, is the sum of the diagonal elements of $A$.
} 


\section{B. The $P^{*}$ model}

In the $P^{*}$ model, the first row in matrix $A, A_{1}$, is simply replaced by

$$
A_{1 .}=\sum_{j=1}^{4} \alpha_{\pi j} e_{j}+\alpha_{m} e_{10}-\alpha_{m} e_{15} .
$$

All other equations remain the same.

\section{Strict monetary targeting without interest-rate smoothing}

Consider strict monetary targeting without interest-rate smoothing, $\lambda_{\mu}=1$ and $\lambda_{\pi}=\lambda_{y}=$ $\lambda_{\Delta i}=0$. We realize that a first-order condition for a minimum of (A.1) is then simply

$$
\mu_{t+1 \mid t}=0
$$

where for any variable $x_{t}, x_{t+\tau \mid t}$ denotes the expectation of $x_{t+\tau}$ conditional on the information available in period $t$, that is, $X_{t}$ and $i_{t}$. From (2.6) and (2.10), we get

$$
\begin{aligned}
\mu_{t+1 \mid t} & \equiv m_{t+1 \mid t}-m_{t-3}+\bar{\pi}_{t+1 \mid t} \\
& =\Delta m_{t+1 \mid t}+m_{t}-m_{t-3}+\bar{\pi}_{t+1 \mid t} \\
& =-\kappa_{m}\left(m_{t}-q_{t}+\kappa_{i} i_{t}\right)+\kappa_{1} \Delta m_{t}+m_{t}-m_{t-3}+\bar{\pi}_{t+1 \mid t} .
\end{aligned}
$$

Combining this with (C.1), solving for $i_{t}$ and using (2.1) gives

$$
\begin{aligned}
i_{t} & =\frac{1}{\kappa_{m} \kappa_{i}} \bar{\pi}_{t+1 \mid t}+\frac{1}{\kappa_{i}} q_{t}-\frac{1}{\kappa_{i}} m_{t}+\frac{\kappa_{1}}{\kappa_{m} \kappa_{i}} \Delta m_{t}+\frac{1}{\kappa_{m} \kappa_{i}}\left(m_{t}-m_{t-3}\right) \\
& =\frac{1}{4 \kappa_{m} \kappa_{i}}\left(\pi_{t+1 \mid t}+\sum_{j=0}^{2} \pi_{t-j}\right)+\frac{1}{\kappa_{i}}\left(y_{t}+q_{t}^{*}\right)+\left(\frac{1+\kappa_{1}-\kappa_{m}}{\kappa_{m} \kappa_{i}}\right) m_{t}-\frac{\kappa_{1}}{\kappa_{m} \kappa_{i}} m_{t-1}-\frac{1}{\kappa_{m} \kappa_{i}} m_{t-3} .
\end{aligned}
$$

Using (2.1) and the empirical estimates, we get

$$
i_{t}=3.10 \pi_{t}+1.71 \pi_{t-1}+2.38 \pi_{t-2}+.21 \pi_{t-3}+1.08 y_{t}+.80 q_{t}^{*}+11.08 m_{t}-4.47 m_{t-1}-7.41 m_{t-3} .
$$

\section{The correlation between inflation forecasts and the money-growth indicator}

Let $\bar{\pi}_{t+T \mid t}$ denote the "equilibrium" inflation forecast (of four-quarter inflation $T$ quarters ahead), that is, the forecast conditional on the optimal reaction function (2.12) and the current state of the economy, $X_{t}$. By (A.8)-(A.11), it is given by

$$
\bar{\pi}_{t+T \mid t}=C_{1} \cdot X_{t+T \mid t}=C_{1} \cdot M^{T} X_{t} \equiv a_{T} X_{t}
$$


where $C_{j}$. denotes the $j$ th row of the matrix $C$.

Let $\bar{\Pi}_{t+T \mid t}\left(i_{t-1}\right)$ denote the "unchanged-interest-rate" inflation forecast (of four-quarter inflation $T \geq 1$ quarters ahead), that is, the forecast conditional on an unchanged interest rate, $i_{t+\tau}=i_{t-1}$ for $\tau \geq 0$, and the current state of the economy, $X_{t}$. We note that

$$
i_{t-1}=e_{7} X_{t}
$$

and define

$$
\begin{aligned}
\tilde{M} & \equiv A+B e_{7} \\
\tilde{C} & \equiv C_{X}+C_{i} e_{7} .
\end{aligned}
$$

Then the unchanged-interest-rate forecast is given by

$$
\bar{\Pi}_{t+T \mid t}\left(i_{t-1}\right)=\tilde{C}_{1} \cdot X_{t+T \mid t}=\tilde{C}_{1} \cdot \tilde{M}^{T} X_{t} \equiv \tilde{a}_{T} X_{t}
$$

Furthermore, in equilibrium we can write

$$
\mu_{t}=C_{3} \cdot X_{t} \equiv b X_{t}
$$

It follows that

$$
\operatorname{Corr}\left[\bar{\pi}_{t+T \mid t}, \mu_{t}\right]=\frac{\operatorname{Cov}\left[\bar{\pi}_{t+T \mid t}, \mu_{t}\right]}{\sqrt{\operatorname{Var}\left[\bar{\pi}_{t+T \mid t}\right] \operatorname{Var}\left[\mu_{t}\right]}}=\frac{a_{T} \Sigma_{X X} b^{\prime}}{\sqrt{a_{T} \Sigma_{X X} a_{T}^{\prime} b \Sigma_{X X} b^{\prime}}}
$$

Similarly,

$$
\operatorname{Corr}\left[\bar{\Pi}_{t+T \mid t}\left(i_{t-1}\right), \mu_{t}\right]=\frac{\tilde{a}_{T} \Sigma_{X X} b^{\prime}}{\sqrt{\tilde{a}_{T} \Sigma_{X X} \tilde{a}_{T}^{\prime} b \Sigma_{X X} b^{\prime}}}
$$

\section{E. Nominal-GDP-growth targeting}

Nominal-GDP-growth targeting requires expanding the vector of state variables by the four variables $q_{t-1}, q_{t-2}, q_{t-3}$ and $q_{t-4}$. Then, the $19 \times 1$ vector $X_{t}$ of state variables, the $19 \times 19$ 
matrix $A$, the $19 \times 1$ column vector $B$, and the $19 \times 1$ column disturbance vector $u_{t}$ are given by

$$
X_{t}=\left[\begin{array}{c}
\pi_{t} \\
\pi_{t-1} \\
\pi_{t-2} \\
\pi_{t-3} \\
y_{t} \\
y_{t-1} \\
i_{t-1} \\
i_{t-2} \\
i_{t-3} \\
m_{t} \\
m_{t-1} \\
m_{t-2} \\
m_{t-3} \\
m_{t-4} \\
q_{t}^{*} \\
q_{t-1} \\
q_{t-2} \\
q_{t-3} \\
q_{t-4}
\end{array}\right], A=\left[\begin{array}{c}
\sum_{j=1}^{4} \alpha_{\pi j} e_{j}+\alpha_{y} e_{5} \\
e_{1} \\
e_{2} \\
e_{3} \\
\beta_{r} e_{1: 4}+\beta_{y 1} e_{5}+\beta_{y 2} e_{6}-\beta_{r} e_{7: 9} \\
e_{5} \\
e_{0} \\
e_{7} \\
e_{8} \\
A_{10} \\
e_{10} \\
e_{11} \\
e_{12} \\
e_{13} \\
e_{15} \\
e_{5}+e_{15} \\
e_{16} \\
e_{17} \\
e_{18}
\end{array}\right], B=\left[\begin{array}{c}
0 \\
0 \\
0 \\
0 \\
-\beta_{r} / 4 \\
0 \\
1 \\
0 \\
0 \\
-\kappa_{m} \kappa_{i} \\
0 \\
0 \\
0 \\
0 \\
0 \\
0 \\
0 \\
0 \\
0 \\
0 \\
0 \\
0 \\
0 \\
0 \\
0 \\
0 \\
0 \\
0 \\
0 \\
0 \\
\xi_{t} \\
0 \\
0 \\
0 \\
0 \\
0 \\
\theta_{t} \\
0 \\
0 \\
0 \\
0 \\
0 \\
0 \\
0
\end{array}\right], u_{t}
$$

where $e_{j}$ and $e_{j: k}(j<k)$ now denotes $1 \times 19$ row vectors.

Furthermore, the $5 \times 1$ vector $Y_{t}$ of goal variables, the $5 \times 19$ matrix $C_{X}$ and the $5 \times 1$ column vector $C_{i}$ are given by

$$
Y_{t}=\left[\begin{array}{c}
\bar{\pi}_{t} \\
y_{t} \\
\mu_{t} \\
i_{t}-i_{t-1} \\
g_{t}
\end{array}\right], C_{X}=\left[\begin{array}{c}
e_{1: 4} \\
e_{5} \\
e_{1: 4}+e_{10}-e_{14} \\
-e_{7} \\
e_{1: 4}+e_{5}+e_{15}-e_{19}
\end{array}\right], C_{i}=\left[\begin{array}{l}
0 \\
0 \\
0 \\
1 \\
0
\end{array}\right],
$$

and the $5 \times 5$ weight matrix $K$ has the diagonal $\left(\lambda_{\pi}, \lambda_{y}, \lambda_{\mu}, \lambda_{\Delta i}, \lambda_{g}\right)$ and all its off-diagonal elements are equal to zero.

\section{References}

[1] Chow, Gregory C. (1970), Analysis and Control of Dynamic Economic Systems, John Wiley and Sons, New York.

[2] Sargent, Thomas L. (1987), Dynamic Macroeconomic Theory, Harvard University Press, Cambridge MA. 